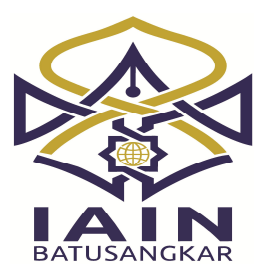

\title{
Developing Islamic Content-Based Materials in Teaching Vocabulary at English Department of Tarbiyah and Teacher Training Faculty of IAIN Batusangkar
}

\author{
Hendra EkaPutra*) \\ Jurusan TadrisBahasa Inggris Institut \\ Agama Islam Negeri Batusangkar \\ Korespondensi: Jorong Balai Batu Lima \\ Kaum Batusangkar \\ email:hendraeka.putra1976@gmail.com
}

\begin{abstract}
Due to the limited sources of Vocabulary teaching materials, the researcher was eager to design a model of vocabulary materials assumed needed by te students for their daily conversation. The design was a Research and Development applying descriptive procedure of three model suggested by Borg and Gall (1983) who propose three ways of developing a model of teaching material, namely: procedural, conceptual, theoretical."'Then, he followed the research procedure by Sugiyono (2007: 298)suggesting ten steps of a research and development: (1) identifying research problem, (2) collecting information, (3) designing the product, (4) validating the design, (5) revising the design, (6) testing the product, (7) revising the product, (8) applying the design, (9) re-revising the product, and (10) publishing the prooduct. In validating the model, he asked some comments from experts. Because of limited time and other reasons of doing the research, he just applied the step 1 up to 4 . Based on the validation result, it could be concluded that the model had fulfilled the criteria both content and construct validity.
\end{abstract}

Kata Kunci: Teaching Material Development, Vocabulary, Islamic Content Based

\section{PENDAHULUAN}

Berbagai upaya telah dilakukan untuk meningkatkan kompetensi komunikasi mahasiswa dalam berbahasa Inggris, baik lisan maupun tulisan. Namun, masih banyak mahasiswa yang menghadapi kendala dalam berbahasa Inggris. Ini dapat terjadi karena banyak faktor yang berkontribusi, seperti: menarik ataupun tidaknya media yang digunakan, ketersediaan dan ketersesuaian materi ajar yang digunakan dalam pengajaran, dan faktor internal ataupun eksternal lainnya.

Di dalam kelas, seorang dosen sangat dituntut kejeliannya dalam memilih materi ajar yang sesuai dengan kebutuhan mahasiswanya. Hal ini sejalan dengan apa yang diungkapkan oleh Munir (2013: 1) yang menyatakan bahwa buku ajar sejatinya didesain untuk memenuhi kebutuhan mahasiswa. Ini dikarenakan materi ajar merupakan salah satu dari banyak faktor yang menentukan kesuksesan mahasiswa dalam berkomunikasi dalam kondisi dan situasi apapun. Seorang dosen hendaknya dapat menselaraskan kebutuhan mahasiswa terhadap bahasa Inggris tidak hanya pada konsep umum saja, tetapi juga pada konsep tertentu. Sebagai contoh, seorang dosen bahasa Inggris pada sebuah perguruan tinggi agama Islam sudah semestinya mengajar bahasa Inggris kepada mahasiswa dengan menggunakan materi-materi ajar yang bernuansa keislaman. Tujuannya adalah disamping mahasiswa mendapakan kompetensi berbahasa Inggris, mereka juga dapat memperkuat keyakinan terhadap agama yang dianutnya.

Jika dihubungkan dengan Visi dan Misi Institut Agama Islam Negeri (IAIN) Batusangkar: "Integratif dan Interkonektif dalam Keilmuan, Berkearifan Lokal, 
Bereputasi Global", maka sejatinya materi ajar bisa menjawab kebutuhan mahasiswa yang selaras dengan visi dan misi tersebut. Hal ini seperti yang dikuatkan oleh Munir (2016: 68) bahwa dalam rangka mewujudkan Visi IAIN Batusangkar, dosen dapat mengintegrasikan nilai-nilai keislaman dengan konten bahasa Inggris. Sayangnya, pada saat ini masih sedikit buku (sumber bacaan) yang tersedia. Dan tidak dapat dipungkiri juga bahwa memang banyak artikel-artikel berbahasa Inggris yang bernuansa keislaman yang ditawarkan lewat media elektronik, tetapi jika di hubungkan dengan silabus mata kuliah, belum bisa menjawab kebutuhan mahasiswa.

Melihat fenomena yang demikian, peneliti yang juga sekaligus menjadi pengampu matakuliah vocabularytertarik untuk melihat bagaimana respon mahasiswa Jurusan Tadris Bahasa Inggris Fakultas Tarbiyah dan Ilmu Keguruan Institut Agama Islam Negeri (IAIN) Batusangkar yang sudah mengambil mata kuliah tersebut secara acak terhadap materi ajar yang telah digunakan sebelumnya. Untuk diketahui, materi yang selama ini digunakan adalah materi yang bersumber dari berbagai rujukan: semisal buku, artikel-artikel, dan sumber berbahasa Inggris lainnya. Hal ini tentu saja membutuhkan usaha dan kesabaran dalam mendapatkan materi yang sesuai. Untuk melihat respon mereka, peneliti mencoba menyebarkan angket terbuka. Kemudian, peneliti menganalisis jawaban mereka untuk melihat apakah mereka butuh atau tidak terhadap materi ajar yang lebih bernuansa keislaman. Dari analisis kebutuhan, dapat diketahui bahwa sebagian besar mereka menjawab bahwa mereka memang membutuhkan materi yang bernuansa keislaman.

Disamping peneliti menanyakan kebutuhan mahasiswa melalui angket yang diberikan, peneliti juga sebelumnya menelaah kekuatan dan kekurangan dari bahan-bahan ajar yang digunakan sebagai sumber materi ajar di dalam kelas. Dari analisis yang peneliti lakukan, peneliti dapat mengatakan bahwa topik-topik dan aktifitas yang diangkat dalam buku tersebut sangat bagus, namun latihannya kurang bervariasi. Selain itu, jika dikaitkan dengan mahasiswa Institut Agama Islam Negeri (IAIN) Batusangkar yang suatu masa akan mungkin mengajar di sekolahsekolah yang berbasis keagamaan akan sulit menjawab jika ada murid yang bertanya akan bahasa Inggris sesuatu yang berhubungan dengan konsep ke-Islaman. Hal ini disebabkan karena buku tersebut lebih menonjolkan penguasaan kosakata yang bersifat umum. Terlebih-lebih ada pada beberapa unit materi ajar yang dijadikan sumber, contoh-contohnya lebih berhubungan dengan konsep non-Islam seperti adanya salah satu kata 'Church'.

Olehkarenanya, akan lebih baik dan dipandang perlu untuk melakukan penelitian ini dengan tujuan bisa menjawab kebutuhan mahasiswa dalam berbahasa Inggris yang sejalan dengan visi dan misi Institut Agama Islam Negeri (IAIN) Batusangkar. Dari penelitian ini, diharapkan lahirnya sebuah produk materi ajar vocabulary yang dapat menjawab kebutuhan mahasiswa tersebut.

\section{Pengembangan Model}

Para ahli mendefinisikan materi ajarbervariasi.AECT (1977) dalam Darmayenti (2011) mendefinisikan pengembangan model ajar sebagai:" $a$ systematic approach to design, production, evaluation, and utilization of complete system of instruction including all appropriate components and a management pattern using them; instructional development is larger than instructional product development which is concerned with only isolated product, and is larger than instructional design, which is only one phase of instructional development."Dapat dikatakan bahwa pengembangan pembelajaran adalah sebuah pendekatan sistematis dalam mendesain, memproduksi, mengevaluasi, dan memamfaatkan sistem pemebelajaran 
yang lengkap yang meliputi segala komponen sistem yang secara tepat.

Selanjutnya, Departemen $\mathrm{P}$ dan K dalam Darmayenti (2011, 104) menyatakan bahwa:"Model ajar adalah sebuah pola (contoh, acuan, ragam) dari sesuatu yang akan dibuat atau dihasilkan."Sedangkan, Richey dan Nelson dalam Darmayenti (2011: 55) mendefinikan penelitian pengembangan sebagai suatu kajian sistematis terhadap pendesainan, pengembangan dan evaluasi program, proses dan produk pembelajaran yang harus memenuhi kriteria validitas, praktikalitas dan efektivitas.

Sementara itu, Suparman (2001: 30) mengatakan bahwa pengembangan lebih menitikberatkan pada tujuannya, diantaranya: pemecahan masalah, peningkatan kualitas kegiatan pembelajaran, atau penciptaan situasi dan kondisi belajar yang memungkinkan peserta didik berinteraksi sihingga terjadi perubahan perilaku malalui suatu proses yang meliputi desain, produksi, dan evaluasi.

Dari teori yang dikutip diatas dapat disimpulkan bahwa model merupakansesuatu contoh atau sistem yang baik yang dapat ditiru oleh orang lain. Dengan kata lain, model dapat dibuat berdasarkan panduan dan apa yang menjadikan kebutuhan sesorang.

\section{Materi Ajar}

Ada beberapa pandangan ahli terkait materi ajar.Tomlinson (1998: 2) mengatakan bahwa materi ajar merupakan segala sesuatu yang digunakan oleh guru atau siswa dalam upaya memudahkan belajar bahasa sehingga dapat meningkatkan pengetahuan dan/atau pengalaman berbahasa.

Sejalan dengan teori Tolimson di atas, Kemp (1985: 149) mengelompokkan materi ajar menjadi dua yaitu: materi audio visual yang sudah tersedia atau yang dibuat sendiri, dan materi lainnya, termasuk materi cetak seperti information sheets, study guides, worksheet, dan workbooks.

Berdasarkan teori di atas, jelas bahwa materi ajar dalam konteks pembelajaran bahasa Inggris adalah semua materi cetak, non-cetak dan materi yang berasal dari beberapa sumber lainnya yang dapat digunakan dalam upaya meningkatkan pengetahuan dan/atau pengalaman berbahasa Inggris seorang individu atau sekumpulan orang yang sedang belajar bahasa.

\section{Prinsip Prinsip Pengembangan Materi Ajar}

Ada beberapa hal yang harus dipertimbangkan dalam mengembangkan materi ajar. Salah satunya adalah mempertimbangkan apakah materi ajar tersebut bisa menjawab kebutuhan peserta didik atau tidak. Ini sejalah dengan apa yang disampaikan oleh Mashura (2003: 351) yang mengatakan bahwa: "bahan ajar harus mampu menarik minat pembelajar dengan cara menyeleksi bahan yang cocok untuk pengajaran."

Tomlinson dalam Richard (2001: 263) mengatakan bahwa ada beberapa prinsip dalam mengembangan materi ajar. Adapun prinsip-prinsip tersebut adalah:

1. Materi ajar harus punya pengaruh yang kuat.

2. Materi ajar harus bisa memudahkan pembelajar.

3. Materi ajar harus mampu meningkatkan kepercayaan diri pembelajar.

4. Materi ajar harusrelevan dan bermanfaat.

5. Materi ajar haus mampu memberikan poin penting terhadap pembelajar.

6. Materi Ajar harus dapat memberikan kesempatan yang sama kepada setiap pembelajar dalam menggunakan bahasa agar tercapai tujuan komunikasi.

7. Materi ajar harus menjamin pembelajar dalm mendapatkan manfaat positif setelah melalui proses belajar. 
8. Materi ajar harus mampu mengakomodasi perbedaan model belajar.

9. Materi ajar harus mampu menjamin pembelajar memiliki perbedaan sikap.

10. Materi ajar harus memberikam kesempatan berfikir di awal pembelajaran.

11. Materi ajar harus mampu memberikan umpan balik.

\section{Jenis-jenis Materi Ajar}

Ada beberapa jenis materi ajar. Tolimson (1998:2) dalam Munir (2013) mengelompokkan materi ajar menjadi beberapa jenis. Jenis-jenis materi ajar tersebut adalah:

1. Materi Tulisan (printed materials)

Contoh jenis ini adalah buku teks, lembaran kerja siswa, gambar, foto, koran, majalah, dan sebagainya.

2. Materi Audio (audio materials)

Contoh jenis ini adalah kaset dan compact disk.

3. Materi Audio visual (audio visual materials)

Contoh jenis ini adalah video compact disk (VCD)dan film.

4. Materi Ajar Interaktif (interactive teaching materials)

Contoh jenis ini adalah materi pembelajaran berbasis web ataucomputer assisted instruction.

Otentik ataupun tidaknya materi ajar didasarkan atas dari mana sumber itu berasal. Nunan (1995) mengatakan bahwa materi otentik adalah materi yang tidak dibuat khusus dan tidak diedit untuk pembelajar bahasa. Beberapa contoh materi ajar yang sifatnya otentik diantaranya adalah film, teks lahu, koran, majalah dan sejenisnya. Sementara nonotentik materi adalah materi yang dirancang untuk tujuan khusus seperti pembelajaran bahasa diman teks-teks yang kuran otentik dapat dimodifikasi disesuaikan dengan kebutuhan. Dapat dikatakan bahwa bahan ajar dapar dirancang sesuai dengan kebutuhan pengajaran. Dalam penelitian ini, peneliti mencoba mendesain materi ajar berdasarkan topik dalam bentuk materi tulisan (printed materials) yang berbentuk buku teks yang menggunakan bahan yang bersifat otentik dan semi-otentik.

\section{Teknik Pengembangan Materi Ajar}

Ada beberapa langkah strategis yang dapat dilakukan dalam mengembangkanmateri ajar. Menurut Kementrian Pendidikan Nasional (2009) dalam Munir (2014: 6) memberikan panduan untuk mengembangkan materi ajar, yaitu dengan cara kategori plus, kategori minus, dan kategori nol. Pengkategorian cara materi ajar dikembangkan dapat dilihat pada tabel dihalaman selanjutnya.

Tabel 1.

Teknik Mengembangkan Materi Ajar (Diknas, 2009: 14-15)

\section{Kategori Plus}

\begin{tabular}{|c|l|l|}
\hline No & \multicolumn{1}{|c|}{ Teknik } & \multicolumn{1}{|c|}{ Contoh } \\
\hline 1 & Menambahkan & $\begin{array}{l}\text { Guru dapat menambahkan } \\
\text { teks dan atau aktivitas } \\
\text { yang berbeda }\end{array}$ \\
\hline 2 & Memperluas & $\begin{array}{l}\text { Guru dapat memperluas } \\
\text { teks dan aktivitas dengan }\end{array}$ \\
& & $\begin{array}{l}\text { meningkatkan panjang } \\
\text { teks, kesulitannya, dan } \\
\text { kedalamannya. }\end{array}$ \\
\hline
\end{tabular}

\begin{tabular}{|c|c|c|}
\hline \multicolumn{3}{|c|}{ Kategori Minus } \\
\hline No & Teknik & Contoh \\
\hline 1 & Membuang & $\begin{array}{l}\text { Guru dapat membuang } \\
\text { beberapa teks dan atau } \\
\text { aktivitas secara bersamaan }\end{array}$ \\
\hline 2 & Mensubstraksi & $\begin{array}{l}\text { Guru dapat mengurangi } \\
\text { jumlah kalimat dalam teks } \\
\text { atau bagian dari aktivitas. }\end{array}$ \\
\hline 3 & Mengurangi & $\begin{array}{l}\text { Guru dapat mengurangi } \\
\text { teks dan aktivitas dengan } \\
\text { mengurangi panjang teks, } \\
\text { kesulitannya, dan } \\
\text { kedalamannya }\end{array}$ \\
\hline
\end{tabular}

\begin{tabular}{|c|c|c|}
\hline \multicolumn{3}{|c|}{ Kategori Nol } \\
\hline No & Teknik & Contoh \\
\hline 1 & Memodifikasi & $\begin{array}{lr}\text { Guru dapat } & \text { membuat } \\
\text { perubahan } & \text { pada } \\
\text { pembelajaran } & \\
\end{array}$ \\
\hline 2 & Mengganti & $\begin{array}{l}\text { Guru dapat mengganti satu } \\
\text { aktivitas dengan aktivitas } \\
\text { lainnya. }\end{array}$ \\
\hline 3 & Mengorganisasi & $\begin{array}{l}\text { Guru dapat mengubah } \\
\text { posisi teks dan ilustrasi }\end{array}$ \\
\hline 4 & Mengurutkan & $\begin{array}{l}\text { Guru dapat mengubah } \\
\text { urutan aktivitas }\end{array}$ \\
\hline 5 & Mengkonversi & $\begin{array}{l}\text { Guru dapat mengubah } \\
\text { genre teks, atau } \\
\text { memindahkan isi dari satu } \\
\text { tempat ke tempat lainnya. }\end{array}$ \\
\hline
\end{tabular}


Sementara Islam dan Mares (2003) dalam Munir (2014:7) membedakan teknik pengembangan materi ajar menjadi: menambahkan,membuang, menyederhanak an, mengurutkan, dan mengganti. Uraian dari teknik-teknik ini dapat dilihat pada penjelasan dibawah ini.

1. Menambahkan

Pada teknik ini, perangcangan materi dapat menambahkan materi lainnya. Hal ini dapat dilakukan dengan dua cara, yaitu: memperluas (lebih mengacu ke kuantitas) dan memperdalam (lebih mengacu ke kualitas).

2. Membuang

Pada teknik ini, perancangan materi juga dapat dilakukan dengan cara membuang bagian-bagian tertentu yang bersifat kuantitatif, menghilangkan bagian-bagian tertentu dan memfokuskan perhatian pada yang lainnya (lebih mengacu ke perubahan kualitas).

3. Menyederhanakan

Perancanganmateri dapat juga dilakukan dengan mengurangi panjangnya teks agar pembelajar dapat memahami teks lebih mudah.

4. Mengurutkan

Perancanganmateri dapat dilakukan dengan mengurutkan satu kegiatan dengan cara yang berbeda sehingga lebih membuat pembelajaran terlihat lebih sistematis.

5. Mengganti

Perancangan materi dapatdilakukan dengan mengganti materi yang ada dengan mempertimbangkan alasan ketertarikan pada budaya tertentu dan alasan lainnya.

Berdasarkan uraian diatas, dapat disimpulkan bahwa berbagai teknik dapat dilakukan dalam mengembangkan materi ajar, seperti menambahkan, mengganti, menyederhanakan, dan memodifikasi. Satu hal yang tidak kalah pentingnya adalah pemilihan teknik tersebut harus didasarkan pada kecocokkannya dengan kebutuhan pembelajar.

\section{Kosakata (Vocabulary)}

Kosakata (vocabulary)sangat penting dalam pengajaran bahasa, khusunya bahasa Inggris sebagai bahasa asing. Oleh karena itu, pembelajar bahasa harus terus meningkatkan kosakata bahasa Inggrisnya jika mereka ingin memiliki kemampuan yang mempuni dalam berbahasa. Sebagai contoh, seorang dosen harus mempertimbangkan ketersesuaian materi ajardalam pengajaran kosakata untuk mahasiswa. Finocchiaro (1981: 16) mengatakan bahwa: "At the beginning level, it should be given to the vocabulary that is intimately related to the environment and experiences of the students.'Dapat diartikan bahwa kosakata yang diberikan kepada pembelajar seharusnya berhubungan dengan lingkungan dan pengalaman yang dialaminya.Dan, masih banyak pendapat ahli lainnya terkait definisi kosakata.

\section{Jenis-jenis Kosakata (Vocabulary)}

Ada beberapa tipe atau jenis kosakata menurut ahli. Robinnet (1980:133)menyatakan bahwa kosakata dapat dibagi menjadiproductive danreceptive vocabulary. Productive vocabularyadalah kosakata yang digunakan dalam komunikasi harian. Sementara, receptive vocabulary menjawab kata-kata yang tidak penting dalam aktifitas berbicara dan menulis.

Sedangkan, Sen dan Haycraft (1983: 12) mengatakan bahwa ada dua jenis kosakata, yaitu: active danpassive vocabulary.Active vocabularymuncul dalam bahasa lisan. Ini merujuk kepada pernyataan-pernyataan yang dapat dipahami, diucapkan, dan dapat dikoreksi dalam aktifitas berbicara dan menulis. Sementara, Passive vocabulary dianggap dan dipahami ketika muncul bersama kontek, tetapi sulit diucapkan dengan benar.

Selanjutnya, Finocchiaro and Bonomo (1973: 83-84) menyatakan bahwa kosakata dapat dikategorikan menjadi: function worddancontent word.The function word 
sangat dekat dengan apa yang diajarkan di dalam kelas seperti kita tidak bisa begitu saja menambahkan kata bantu atau struktur kata dalam bahasa semaunya kita. Sedangkan, the content word memungkinkan kita menambahkan katakata baru ataupun bahasa tentang temuantemuan penting.

Dari pendapat ahli di atas, dapat dilihat ada beberapa tipe atau jenis kosakata. Tipe atau jenis kosakata tersebut bervariasi dalam istilah. Namun, seluruhnnya mengacu pada dua hal yang berbeda dalam pemanfaatannya dalam komunikasi, lisan atau tulisan.

\section{Pentingnya Kosakata(Vocabulary)}

Banyak ahli yang berpendapat tentang pentingnya kosakata dalam meningkatkan kemampuan berbahasa. Schleiffer di dalam Supia (2003: 12) menyatakan bahwa:

"What goes in the classroom has been the subject of many studies with sometimes-contradictory result. Vocabulary is basic lesson in language. Without mastering vocabulary, we are not able to use the language, and every language has grammatical patterns that relate vocabulary."

Teori ini dapat diartikan bahwa apa yang didapat di dalam kelas bisa saja tidak sejalan dengan apa yang mungkin terjadi dikeseharian. Kosakata merupakan pelajaran utama dalam bahasa. Tanpa kosakata kita tidak dapat berbahasa dan setiap bahasa memiliki pola kalimatnya sendiri yang terkait dengan kosakata.

Selanjutnya, Krakawian di dalam Supia(2003: 12) menyatakan bahwa:

"In communication oriented teaching the most pressing concern for the learners is the need to master an adequate foreign language vocabulary. It seems that vocabulary is very important. But we cannot separate them from other elements of language and from the four language skills."
Berdasarkan teori ini dapat dikatakan bahwa komunikasi yang diorientasikan dalam pengajaran lebih difokuskan kebutuhan maha/siswa terhadap kosakata bahasa asing tertentu. Makanya kosakata menjadi penting. Tetapi kita tidak dapat memisahkannya dari elemen bahasa dan keempat keahlian berbahasa yang lainnya.

Dari pendapat ahli di atas, dapat disimpulkan bahwa kosakata sangat penting dalam berbahasa. Kosakata dapat digunakan sesuai dengan kebutuhan berbahasa, baik lisan ataupun tulisan. Tetapi yang mesti diingat adalah setiap bahasa memiliki pola bahasa dan maknamakna tersendiri.

\section{Pengajaran Bahasa Inggris di Perguruan Tinggi}

Pengajaran Bahasa Inggris di perguruan tinggi merupakan sebuah kewajiban (cumpolsory subject). Pada Jurusan Tadris Bahasa Inggris Fakultas Tarbiyah Institut Agama Islam Negeri (IAIN) Batusangkar seluruh mahasiswa diwajibkan mengambil mata kuliah vocabulary pada semester I. Matakuliah tersebut diambil agar mahasiswa dapat terbantu menambah kosakatanya secara sistematis dan terstruktur di dalam ataupun di luar kelas sesuai dengan kebutuhan berkomunikasi mereka. Meskipun, materi ajar yang diberikan masih bersifat umum dan belum sejalan dengan visi dan misi Institut Agama Islam Negeri (IAIN) Batusangkar.

\section{METODE PENGEMBANGAN}

Ada banyak model yang dapat digunakan oleh seorang peneliti dalam penelitiannya. Borg dan Gall (1983) menyatakan bahwa model pengembangan dapat dikembangkan atas tiga model: prosedural, konseptual, dan teoritik. Dengan merujuk teori ini, peneliti memilih model pengembangan prosedural yang bersifat deskriptif. Maksudnya adalahpeneliti merancang model materi ajar dengan menetapkan langkah-langkah 
tertentu agar produk yang diinginkan dapat dihasilkan.

\section{Langkah-langkah Penelitian dan Pengembangan}

Dalam penelitian ini, peneliti menerapkan langkah-langkah penelitian dan pengembangan yang dianjurkan olehSugiyono (2007: 298), Richards (2001: 264) dan Jolly dan Bolitho (dalam Tomlinson, 1998- 97-98). Sugiyono (2007: 298) mengatakan bahwa ada beberapa langkah penelitian pengembangan yaitu: (1) Identifikasi masalah, (2) Pengumpulan informasi, (3) Desain produk, (4) Validasi desain, (5) Perbaikan desain, (6) Uji coba produk, (7) Revisi produk, (8) Uji coba pemakaian, (9) Revisi produk tahap akhir, dan (10) Produksi massal.

Kemudian, Richards (2001: 264) mengatakan bahwa ada sejumlah tahapan yang mesti dilakukan untuk mengembangkan materi ajar yaitu: (1) Pengembangan tujuan umum, (2) Pengembangan tujuan khusus, (3) Pengembangan silabus, (4) pengorganisasian materi ajar ke dalam unit-unit, (5) pengembangan struktur untuk masing-masing unit, dan (6) pengurutan unit.

Selanjutnya, Jolly dan Bolitho (dalam Tomlinson, 1998: 97-98) menyatakan bahwa ada tujuh langkah dalam pengembangan materi ajar, yaitu: (1) Melakukan identifikasi kebutuhan akan materi ajar atau permasalahan yang akan dipecahkan,(2)Melakukan eksplorasi terhadap apa saja yang berhubungan dengan kebutuhan atau permasalahan tersebut, seperti bahasa apa, makna apa, fungsi-fungsi apa, keterampilanketerampilan berbahasa apa saja yang dibutuhkan,(3)Melakukan realisasi kontekstual terhadap materi-materi ajar yang diusulkan (dapat ditempuh adalah dengan mencari ide-ide, konteks, atau teks yang sesuai),(4)Melakukan realisasi pedagogis terhadap materi ajar yang akan dikembangkan (dapat diwujudkan dengan cara menemukan latihan-latihan dan aktivitas-aktivitas yang tepat dan menuliskan petunjuk-petunjuk yang tepat untuk digunakan,(5) Produksi fisik materi ajar, yang meliputi pertimbangan akan tata letak, jenis ukuran, tampilan, reproduki, panjangnya tapedan lain-lain, (6)Penggunaan materi ajar oleh pembelajar bahasa, (7)Evaluasi materi ajar berdasarkan tujuan yang telah ditetapkan.

Dalam penelitian ini, peneliti menggabungkan ketiga teori pakar di atas.Berikut adalah langkah-langkah penelitian yang telah peneliti lakukan sejauh ini.

1. Identifikasi Masalah

Pada tahap ini, peneliti telah mengidentifikasi masalah tentang kebutuhan mahasiswa jurusan tadris Bahasa Inggris fakultas Tarbiyah Institut Agama Islam Negeri (IAIN) Batusangkar yang mengambil mata kuliah Vocabulary terkait materi ajar pada matakuliah tersebut. Peneliti telah memberikan angket terbuka mahasiswa untuk mendapatkan respon terkait materi ajar vocabulary dan tentang kemungkinan kebutuahn mereka terhadap materi ajar vocabulary yang bernuansa keislaman.

2. Pengumpulan Informasi

Pada tahap ini, peneliti telah mengumpulkan informasi tentang model materi ajar Vocabulary yang sesuai dengan kebutuhan mahasiswa yang dapat meningkatkan kemampuan berbahasa mereka. Oleh karenanya,segala yang berhubungan dengan kebutuhan atau permasalahan tersebut, seperti bahasa apa, makna apa, fungsi-fungsi apa, keterampilanketerampilan berbahasa apa saja yang dibutuhkan dieksplor. (Sugiyono, 2007: 298; Jolly dan Bolitho dalam Tomlinson, 1998: 97-98).

3. Desain Produk

Pada tahap ini, peneliti mendesain sebuah materi ajar yang sesuai dengan kebutuhan mahasiswa (Sugiyono, 2007: 298) dengan berpedoman pada sejumlah langkah yang disarankan Richards 
(2001: 264) yang meliputi:

Pengembangan tujuan umum,

Pengembangan tujuan khusus,

Pengembangan silabus,

pengorganisasian materi ajar ke dalam unit-unit, (5) pengembangan struktur untuk masing-masing unit, dan (6) pengurutan unit.

Pada tahapan ini, peneliti mengutip teori Jolly dan Bolitho dalam Tomlinson (1998: 97-98) yang menyatakan bahwa: "Ide-ide, konteks, teks, latihan-latihan dan aktivitasaktivitas belajar yang tepat dapatdimasukkan ke dalam materi ajar dan petunjuk-petunjuk tentang cara menggunakan materi ajar tersebut juga dapat dituliskan."Secara akademis, peneliti mengembangkan materi ajar dengan menemukan bentuk-bentuk latihan yang dipandu dengan petunjuk latihan yang sesuai dengan kebutuhan mahasiswa tersebut. Terkait latihan ini, peneliti telah mendesain model dengan merujuk teori Jolly dan Bolitho dalam Tomlinson (1998: 97-98) dimana ada beberapa pertimbangan terkait produk yang dihasilkan seperti tata letak, jenis ukuran, tampilan, reproduki, panjangnya tape dan lain-lainnya.

4. Validasi Desain

Pada tahap ini, peneliti meminta masukan dari spakar dalam bidang bahasa Inggris (expert judgement) tentang materi ajar yang akan dikembangkanuntuk validasi desain (Sugiyono, 2007: 298). Dengan kata lain, peneliti mengevaluasi materi ajar berdasarkan tujuan yang telah ditetapkan sesuai pendapat pakar (Jolly dan Bolitho dalam Tomlinson, 1998: 97-98).

\section{Subjek Uji Coba Penelitian}

Dikarenakan keterbatasan waktu, penelitian ini baru pada tahap validasi desain. Sehingga, uji coba prodak penelitian terhadap subjek uji coba yaknimahasiswa jurusan Tadris Bahasa Inggris Fakultas Tarbiyah Institut Agama
Islam Negeri (IAIN) Batusangkaryang sedang mengambil matakuliah Vocabularypada semester ganjil 20162017 ini tidak terealisasi.

\section{Data dan Sumber Data}

Yang menjadi data penelitian ini adalah data kualitatif berupa komentar, kritikan, dan saran yang bersumber dari pakar yang berasal dari Institut Agama Islam (IAIN) Batusangkar sendiri.

\section{Teknik Pengumpulan Data}

Data penelitian dan pengembangan ini dikumpulkan dengan menggunakan angketterbuka. Angket tersebut diberikan kepada dua orang pakar pakar untuk mendapakan data kualitatif tentang model materi ajar yang telah didesain.

\section{Teknik Analisis Data}

Data kualitatif yang diperoleh melalui angket tersebutdianalisis dengan menggunakan model analisis data Miles dan Huberman (1994).

\section{HASIL DAN PEMBAHASAN}

Dari hasil validasi dari model materi ajarVocabularyyang dirancang untuk mahasiswa jurusan Tadris Bahasa Inggris Fakultas Tarbiyah Institut Agama Islam Negeri (IAIN) Batusangkar dibahas 3 hal penting, yaitu: 1) hasil analisis kebutuhan (need analysis), 2) hasil rancangan prototypemodel materi ajar, dan 3) validasi terhadap rancangan prototypetersebut.

\section{Hasil Analisis Kebutuhan (Need Analysis)}

Kebutuhan mahasiswa terkait perlunya sebuah materi ajar Vocabulary tersebut diperoleh ketika peneliti mulai mengampu matakuliah Vocabulary tersebut beberapa tahun yang lalu.Namun, baru pada kesempatan penelitian ini peneliti mencoba untuk merealisasikannya Ini berawal ketika peneliti sulit untuk mengumpulkan bahan ajar dari beberapa sumber yang dianggap sesuai dengan kebutuhan mereka.Dari bincang-bincang 
tersebut, peneliti mengetahui bahwa mereka selama ini (di sekolah) mempelari bahasa Inggris yang kosakatanya masih umum. Ketika peneliti memberikan angket terbuka tentang apa yang menjadi kebutuhan mereka saat ini dimana sedang kuliah di jurusan Bahasa Inggris Fakultas Tarbiyah Institut Agama Islam Negeri (IAIN) Batusangkar, dapat diketahui bahwa sebagian besar dari mahasiswa memberikan saran agar doen pengampu matakuliah Vocabulary mengajarkan kosakata berbahasa Inggris yang bernuansa ke-Islaman, disamping kosakata berbahasa Inggris umumnya.

Oleh karena alasan tersebut, peneliti tertarik mendisain sebuah model materi ajar yang diharapkan menjadi solusi permasalahan mereka tersebut. Dengan adanya model ini diharapkan mereka meningkatkan kosakata bahasa Inggris mereka, terutama sekali kosakata bahasa Inggris yang bernuansa ke-Islaman.

\section{PrototypeModel Materi Ajar yang Dirancang}

Berdasarkan hasil analisis kebutuhan diatas, peneliti merancang model materi ajar tersebut.Adapun perangkat model yang dirancang berupa:

1. Topik-topik setiap unit didasarkan pada silabus matakuliah Vocabulary.

2. Berbagai macam jenis teks yang diambil dari beberapa sumber berbahasa Inggris yang membahas tentang Islam.

3. Kegiatan-kegiatan yang ada pada setiap unit lebih menitikberatkan latihanlatihan yang bisa dilakukan secara individu ataupun berpasangan.

4. Latihan-latihan yang diberikan untuk mengukur pemahaman mereka terhadap kosakata dan teks yang bernuansa keIslaman yang diberikan.

5. Latihan-latihan dan pertanyaanpertanyaan terkait teks bacaan (sebagai bentuk pemahaman mereka terhadap latihan-latihan yang disediakan) berupa Matching, True-False, Get filling, Yesno questions, danwh-questions.
Berikut ini merupakan bentuk prototype yang dirancang untuk Unit 1 . Produk utuh terkait penelitian dapat dilihat pada bagian tersendiri.

\section{UNIT1 \\ TAWHEED: ONENESS OF ALLAH Learning Objective:}

After studying this unit, you are able to understand Islamic terms through identifying part of speech: Noun,Verb, Adjective, and Adverb.

\section{Word Form Chart}

\begin{tabular}{|c|c|c|c|}
\hline Noun & Verb & Adjective & Adverb \\
\hline $\begin{array}{l}\text { calamity } \\
\text { command } \\
\text { comparison } \\
\text { comparability } \\
\text { creator } \\
\text { equal } \\
\text { equality } \\
\text { forgiveness } \\
\text { guidance } \\
\text { guide } \\
\text { hide } \\
\text { mercy } \\
\text { miracle } \\
\text { obedience } \\
\text { power } \\
\text { prophet } \\
\text { sacrifice } \\
\text { sin } \\
\text { sustainance } \\
\text { sustainer } \\
\text { universe } \\
\text { wisdom } \\
\text { worshipper }\end{array}$ & $\begin{array}{c}\text { command } \\
\text { compare } \\
\text { create } \\
\text { equate } \\
\text { equalize } \\
\text { forgive } \\
\text { guide } \\
\text { hide } \\
\\
\text { obey } \\
\text { empower } \\
\text { sacrifice } \\
\text { sin } \\
\text { sustain }\end{array}$ & $\begin{array}{c}\text { comparable } \\
\text { comparative } \\
\text { creative } \\
\text { equal } \\
\text { forgivable } \\
\text { guided } \\
\text { guiding } \\
\text { hidden } \\
\\
\text { obedient } \\
\text { powerful } \\
\text { sacrificial } \\
\text { sinful } \\
\text { sustained } \\
\text { sustaining } \\
\text { universal }\end{array}$ & $\begin{array}{c}\text { comparatively } \\
\text { creatively } \\
\text { equally }\end{array}$ \\
\hline
\end{tabular}

\section{Definition and Examples}

1. Calamity (great disaster)

The calamity will happen to humankind if they do bad things.
A : "Why don't you do that?"
B : "I'm sorry. I can't because of the calamity after doing it."

2. Command (order/ control/ an ability to use)

Allah commandsmoslem people to do compulsory prayers.

A : "My parents usually command me to fast every Ramadhan."

B : "That's good. My parents do too." 
3. Compare (examining things to see how they are alike and how they are different)

I have to compare two things before choosing the best one.

A : "The two pairs of shoes I saw at shoes store made me confused."

B : "Why don't you compare them very carefully?"

4. Creator (person who creates)

Allah is the creator of man, animal, and other creations.

A : "Allah creates us to believe in Allah."

B :"I really agree with you."

5. Equal (the same in size, number, value, etc)

All people are equal.

A : "What do you think about our chance to follow that competition."

B : "Don't worry. We are equal to others."

6. Forgive (bitter towards to stop blaming)

You must forgive him for his mistakes.

A : "Allah never forgive people who do not believe in Allah."

B : "Yes, that's right. Do you think Allah will give Allah's forgiveness eventhough we did something bad in the past."

A : "Yes, as far as you promise to Allah not to do it anymore."

7. Guide (a person who shows others the way; book of information; action as a guide to)

$\mathrm{Al}$-Qur'an guides us to paradise.
A : "I am really up set right now."
B : "You should read Al-Qur'an whenever and wherever you are. It will guide you."

8. Hide (putting or keeping out of sight)
If you don't want someone to see it, you should hide it.

A : "Why do you hide this problem from me?"

B : "I don't want to make you confused me."

9. Mercy (kindness of forgiveness)

Allah's mercy is for all Allah's creatures.

A : "What should I do to get the mercy of Allah?"

B : "I think you have to do all good things."

10. Power (action on how to do something)

Something good and bad happen in the world are the examples of Allah's power.

A : "It's really hard for me to do it. I am not sure I can."

B : "Don't give up. You should believe in the power of Allah."

11. Prophet (person who teaches religion that comes from Allah)

Allah sent Malaaikah to prophet to reveal Allah's revelation.

A : "Prophet Muhammad is the best example for us."

B : "I agree. I think we should follow his words."

12. Sacrifice (offering something valuable to Allah)

Moslem sacrifice themselves to Allah in order to help needy.

A : "Have you sacrificed, Dani?"

B : "Yes, I have."

13. Sin (breaking Allah's laws)

Sin is something when you had done bad things.

A : "Why are you crying Ahmad?"

B : "I'm afraid of Allah. I had done a sin." 
14. Tawheed (The belief that it is Allah alone as the Creator of mankind)

The Belief of Allah alone as the Creator of humankind is known as Tawheed.

A : "Do you believe in Allah that there is no one else except Allah."

B : "Sure. That is Tawheed."

15. Universe (everything that exists in space, including all the stars and planets)

Allah createduniverse to be explored by humanbeings.

A : "Who is the owner of the universe?"

B : "Allah"

16. Wisdom (the quality of being wise)

Everyone competes to get Allah's wisdom.

A : "I am proud of what Ari has done."

B : "That's such kind of wisdom of Allah."

17. Worship (revencing, respecting or loving Allah)

The young girl worhips every time she has heard Adzan."

A : "Have you worship to Allah."

B : "Not yet. I will."

\section{Exercise}

\section{A. Match each word with its definition!}

1. huge or great disaster

2. Allah alone as the creator of mankind $b$.

3. revencing, respecting or loving for Allah to Allah d.

4. offering something valuable

5. bitter towards to stop blaming

e. equal

6. breaking Allah's laws

7. keeping alive or in existence

8. the same in size, number, value, etc $h$.
9. everything that exists in space, including

all the stars and planets

10. person who teaches religion and claims

that his teaching comes from

Allah 1. sacrifice

B. Answer each question with the words from the word chart in this unit!

1. What is something bad that can happen to people who do not obey Allah's order?

2. What is the name of person who teaches religion based on Allah's orders?

3. What should good moslems do when someone does something terrible to them?

4. What is the Who creates the universe and mankind?

5. What is the term of believing Allah alone as the creator of mankind?

C. Write $\mathbf{T}$ if the sentence is true and $\mathbf{F}$ if it is false!

1. ___ Prophet is a person who teaches everything, except religion.

2. Moslems have to obey Allah

3. __ Breaking Allah's laws is a must for Moslems.

4. Allah claims that all people are equal.

5. Moslem people do not need to forgive when others do somethingbad to them.

a. universe

D. In the blanks, write the appropriate word (s) ${ }^{\mathrm{N}}$ prehipthe word chart in this unit!

1. Allahc.ołdetain people to ......... in Allah.

2. As ggalamityslems, people have to ........ Allah's orders.

3. Allah's prophets ...... their followersammandid sin.

4. Peop Prophet.... themselves to Allah to get involved in the paradise.

5. You forgiste ............ something good or bad before doing it. 


\section{E. Read the following text and fill in the blanks with suitable words based on the text!}

\section{Tawheed}

Tawheed is the most important belief in Islam. It means that Allah is One (Supreme), and there is nothing like Allah. Allah says in Surat allkhlaas: "Allah is the One.Allah is the Everlasting Sustainer of all. Allah has not given birth and was not born;And no one is comparable to Allah."

Tawheed means Allah alone is the Creator. Allah is the only powerbehind the universe and the sole source of its guidance. Allah knowseverything, sees everything and has power over everything. Allah isEternal and is beyond human knowledge and reasoning. This doesnot mean that Allah is so far away that Allah cannot possibly know or care about what Allah creates. On the contrary, Allah is closed to all of us. Allah listens to our prayer when we call on to Allah. Allahcreated us, so Allah knows everything about us. In fact, Allah isnearer to us than our jugular veins. Everything in the universe belongs to Allah.

Allah knows everything. If a calamity strikes, it is for a reason Allah knows, even if we do not understand why it has happened.

(Taken from: Islamic Eduaction

Grade Five, Molvi Abdul Aziz,

2011:1)

1. Tawheed

means of Allah.

2. Allah has not given birth and was not

3 prophet.

4. Allah will never forgive.

5. Allah's encompasses all voices.
F. Are these statements true or false? In the box provided, write $T$ if the statement is true or $\mathbf{F}$ if it is false.

1. Allah knows all the secrets we keep in our hearts. (....)

2. Since Almighty Allah was not born, Allah has no father or mother. (...)

3. The key of Tawheed are shahaadah, salah, zakah, sawmand hajj. (....)

4. Our needs are too much for Allah to fulfill. (....)

\section{G. Answer the following questions!}

1. What is Tawheed?

2. What is shirk?

3. Name some attributes of Allah you studied in this unit!

4. Are we allowed to worship rivers, statues, graves, etc.? Why?

5. Whom should weworship, and why?

\section{Hasil Validitas Prototype Model Materi Ajar yang Dirancang}

Model materi ajar yang dikembangkan pada penelitian ini divalidasi oleh dua orang pakar dari Institut Agama Islam Negeri (IAIN) Batusangkar. Hasil validasi dari kedua pakar menunjukkan bahwa ada beberapa revisi yang perlu dilakukan peneliti berkenaan dengan rancangan yang tersebut. Adapun revisi yang perlu dilakukan adalah sebagai berikut:

1. Adanya ketidakkonsistenan dalam pengurutan aktifitas setiap unit pada produk.

2. Kurangnya variasi reduksi terkait 'Learning Objective' pada setiap unit produk yang dapat membuat bosan pembaca, dalam hal ini mahasiswa yang akan memamfaatkan produk ini suatu waktu.

3. Lay-outdan kesalahan pengetikan seperti bergabungnya dua kata yang menyebabkan perubahan makna bahasa yang ditemukan pada produk penelitian.

4. Belum dihitamkannya semua instruksi pada latihan (Exercise) pada setiap unit.

5. Sebagian besar sumber rujukan sudah mencantumkan tahun terbit, tapi masih ada yang belum. 
6. Belum ditebalkannya setiap judul dan sub-judulyang ada dalam produk.

Terkait hasil tersebut, validator juga memberikan beberapa saran untuk kesempurnaan dari strategi membaca yang dikembangkan, yaitu:

1. Perlu adanya ketidakkonsistenan dalam pengurutan aktifitas setiap unit pada produk.

2. Perlumemvariasikan redaksi terkait 'Learning Objective' pada setiap unit produk yang dapat membuat bosan pembaca, dalam hal ini mahasiswa yang akan memamfaatkan produk ini suatu waktu.

3. Perlunya perbaikan Lay-outdan kesalahan pengetikan seperti bergabungnya dua kata yang menyebabkan perubahan makna bahasa yang ditemukan pada produk penelitian.

4. Perlunya menghitamkan semua instruksi pada latihan (Exercise) pada setiap unit.

5. Mencantumkan tahun terbit semua sumber rujukan.

6. Ditebalkannya setiap judul dan subjudulyang ada dalam produk.

Setelah berdiskusi dengan validator dan merevisi model materi ajar tersebut, dapat disimpulkan bahwa:

1. Model materi ajarVocabulary untuk mahasiswa jurusan Tadris Bahasa Inggris Fakultas Tarbiyah Institut Agama Islam Negeri (IAIN) Batusangkar yang dikembangkan berisi latihan-latihan dan teks-teks yang menarik.

2. Kegiatan-kegiatan dalam proses memahami kosakata yang ditawarkan dalam latihan-latihan dapat membantu mahasiswa meningkatkan kosakata bahasa Inggris mereka, terutama sekali yang kosakata yang bernuansa Islam.

3. Latihan dan pertanyaan-pertanyaan terkait masing-masing teks dapat digunakan untuk menguji pemahaman mereka sehingga kemampuan berbahasa Inggris mereka, disamping itu juga dapat menambah keyakinan mereka terhadap agama yang mereka anut.
Berdasarkan apa yang sudah dibahas di atas, dapat disimpulkan bahwa model materi ajar Vocabulary untuk mahasiswa jurusan Tadris Bahasa Inggris Fakultas TarbiyahInstitut Agama Islam Negeri (IAIN) Batusangkar yang dikembangkan memenuhi criteria valid dari segi isi (content validity), dan konstruksinya (construct validity).

\section{KESIMPULAN DAN SARAN Kesimpulan}

Ada beberapa kesimpulan yang dapat diambil dari hasil penelitian ini, yaitu:

1. Setelah melalui tahap analisis kebutuhan, dan perancangan prototype, penelitian ini telah menghasilkan prototypemodel materi ajar Vocabulary untuk mahasiswa jurusan Tadris Bahasa Inggris Fakultas Tarbiyah Institut Agama Islam Negeri (IAIN) Batusangkar yang memberikan kesempatan kepada mahasiswa untuk meningkatkan kosakata bahasa Inggris mereka, baik bahasa Inggris yang umum dipelajari ataupun yang bernuansa ke-Islaman melalui latihanlatihan dan teks-teks dengan panduanpanduan untuk membantu mahasiswa untuk memahami berbagai laitihanlatihan yang ditawarkan.

2. Hasil validasi dari dua orang pakar dan setelah melalui diskusi dan revisi, prototypemodel materi ajarVocabulary untuk mahasiswa jurusan Tadris Bahasa Inggris Fakultas Tarbiyah Institut Agama Islam Negeri (IAIN) Batusangkar ini telah memenuhi criteria valid dari segi isi (content validity) dan juga konstruksinya (contruct validity). Ini berarti bahwa model materi ajar inivaliduntuk digunakan pada matakuliah Vocabulary di jurusan Tadris Bahasa Inggris Fakultas Tarbiyah Institut Agama Islam Negeri (IAIN) Batusangkar.

\section{Saran}

Prototypemodel materi ajar Vocabulary untuk mahasiswa jurusan Tadris Bahasa Inggris Fakultas Tarbiyah 
Institut Agama Islam Negeri (IAIN) Batusangkar yang dirancang pada penelitian ini berisi latihan-latihan dan teks-teks yang pada dasarnya dapat membantu mahasiswa untuk meningkatkan kosakata bahasa Inggris mereka.Dikarenakan prototype ini baru pada tahap validasi, peneliti selanjutnya dapat melihat aspek praktikalitas dan efektifitas dari prototype yang dirancang tersebut untuk penelitian selanjutnya.

\section{DAFTAR PUSTAKA}

Aziz, Molvi Abdul. 2011. Islamic Education Grade Five. London: Darussalam.

Borg, Walter. R dan Gall, Meredith. 1983. Educational Research: An Introduction. New York: Longman Inc.

Chandra, Bhakti Adi. 2014. Developing A prototype of Web-Based Extensive Reading Materials to Improve Vocabulary Acquisition for the Seventh Graders of Junior High School. (Unpublished Thesis). Malang: State University of Malang.

Darmayenti. 2011. Pengembangan Model Mingle dalam Pembelajaran Keterampilan Berbicara Bahasa Inggris di Sekolah Dasar. Padang: Program Pascasarjana Universitas Negeri Padang.

Departemen P dan K. 1984. Kurikulum Pendidikan Dasar dan Menengah. Jakarta: Depdiknas.

Emzir. 2010. Metodologi Penelitian Pendidikan Kuantitatif \& Kualitatif (Edisi Revisi). Jakarta: PT RadjaGrafindo Persada.

Fetria, Fatma Zulita. 2016. Teachers' Strategies in Teacing English Vocabulary (A Study of the
English Teachers of State Junior High Schools Kecamatan Lima Kaum). (Unpublished Thesis). Batusangkar: Sekolah Tinggi Agama Islam Negeri (STAIN) Batusangkar.

Finocchiaro, Marry. 1981. English as a Second Language: From Theory to Practice. New York: Regent Publishing Company.

Hornby, A. S. 1986. Oxford Advanced Learners Dictionary of Current English. London: Oxford University Press.

Kemp, Jerrold E. 1985. The Instructional Deign Process. New York: Harper \& Row Publishers.

Marshefel, Ned D. 1996. Better Reading in Secondary School. New York: Roma Press Company.

McWhorter, Kathleen. 1986. Guide to College Reading. Boston: Little Brown Company.

Miles, Mathew. B dan Huberman, A. Michael. 1984. Qualitative Data Analysis. Los Angeles: Sage Publications, Inc.

Munir, Sirajul. 2013. An Evaluation of Reading Comprehension Textbooks Taught at the English Department of Islamic Higher Education in West Sumatera. Journal at Language and Literature. Vol. VII No. 2

Munir, Sirajul. 2014. Pengembangan Materi Ajar Bahasa Inggris untuk Agen Travel (Sebuah Kajian English For Occupational Purposes). Ragam Jurnal Pengembangan Humaniora Volume 14 No. 13 
Munir, Sirajul dan Hartono R. 2016. Islamic Magazine Articles to Entiance Students' Reading Skill and Build Their Character Values. International Journal of Education 9 No. 1

Richards, Jack. C. 2001. Curriculum Development in Language Teaching. Cambridge: Cambridge University Press.

Robinnet, Betty Wallace. 1980. Teaching English to Speakers of Other language: Substance and Technique. Minneapolis: Minnesota University.

Sen, Ann Lois and Haycraft. 1983. Teaching Vocabulary through Riddles. English Teaching Forum.July. Vol. 44. N.3.

Stojanovic, Milica. 2014. "Creating An EAP/ESP Core Text-Book: Focus on Acquiring Knowledge in English Rather Than About English. The Journal of Teaching English for Specific and Academic Purposes."Vol. 2, No. 1, p.21-23.

Stufflebearn, D., C. McCornick, R. Brinkerhoff, dan C. Nelson. (1985. Conducting Educational Needs Assessment. Hingham, MA: Kluwer-Nijhoff Publishing.
Sugiyono. 2007. Metode Penelitian Kuantitatif, Kualitatif, dan $R \& D$. Bandung: Penerbit Alfabeta.

Suparman, Atwi. 2001. Desain Instruksional: Pusat Antar Universitas untuk Peningkatan dan Pengembangan Aktivitas Instruksional. Jakarta: Direktorat Jenderal Pendidikan Tinggi Depdiknas.

Supia, Dewi. 2003. Teaching Vocabulary through Song. (Unpublished Proposal). Padang: Universitas Bung Hatta.

Tarnopolsky, Oleg and Vysselko, Andriy. 2014. "Mini-Courses on Economic Disciplines in An Advanced ESP Course for University Students of Economic." The Journal of Teaching English for Specific and Academic Purposes."Vol. 2, No. 1, p.45-59.

Tomlinson, Brian. 1998. Materials Development in Language Teaching. Cambridge: Cambridge University Press.

Yulianti, Rusmidah. 2013. Penggunaan Model Word Square dalam Meningkatkan Pengusaan Kosakata Bahasa Inggris Siswa Kelas IV SD. Jurnal FKIP UNS. Vol.1 No.4. 